\title{
Pregnancy-Related Information Need and Information-Seeking Pattern Among Pregnant Women Attending Antenatal Clinic at Ikorodu General Hospital, Lagos State, Nigeria
}

\author{
Ojewole, Foluso Ph.D., Rn \\ Oludipe, Yemisi O., Bnsc, Rn, Rm \\ Department of Adult Health Nursing, Babcock University Ilishan, \\ Ogun State, Nigeria
}

doi: 10.19044/esj.2017.v13n24p436 URL:http://dx.doi.org/10.19044/esj.2017.v13n24p436

\begin{abstract}
Background: Pregnant women attending antenatal care have a need for quality pregnancy-related information. Purpose: To describe the pregnancy-related information seeking patterns among pregnant women attending antenatal clinic in Ikorodu. Methods and Design: The study was carried out using a descriptive correlational design. A purposive sample of 228pregnant women were recruited from an antenatal clinic in Lagos State to complete pregnancy-related information seeking pattern questionnaire (PRISPQ)." Descriptive analysis and inferential statistics (logic regression) was used to analyse the information generated. Result: Over 50\% respondents are in third trimester, age range 26-35years. Majority of the pregnant women in the study area had moderate level of pregnancy information needs $(58.3 \%$, mean $=28.007)$ and information-seeking $(52.2 \%$, mean $=26.119)$. Long wait to see the healthcare personnel $(64.5 \%)$ and having knowledge of pregnancy $(60.5 \%)$ are perceived barriers to seeking pregnancy-related information. The most potent predictor of information seeking pattern among the predictor variables of the study is religion $(\beta=$ $.372 ; \mathrm{t}=8.419 ; \mathrm{p}<.05)$, followed by age $(\beta=.300 ; \mathrm{t}=6.335 ; \mathrm{p}<.05)$, and lastly by marital status $(\beta=.261 ; \mathrm{t}=4.456 ; \mathrm{p}<.05)$. Conclusion: Pregnancy outcomes could be improved if pregnant women are provided with pregnancy-related information necessary to empower them to overcome pregnancy challenges. Thus, nurses and midwives should offer quality information that could assist the pregnant women to make rightful healthcare decision during antenatal.
\end{abstract}


Keywords: Pregnancy-related information, seeking pattern, pregnant women, and antenatal clinic.

\section{Introduction}

Complications from pregnancy is a number one cause of death among women of reproductive age. About 287,000 women dieof pregnancy-related complications each year (World Health Organization, 2015). In Nigeria, 36,000 women experience childbirth related death per year, accounting for about 13 percent of the global maternal death rates (Demographic Health Survey, 2015). As a result, several pregnant women are experiencing pregnancy related fears, concern, and uncertainty. Thus, they settle for the need to acquire more information about the pregnancy. Pregnancy period is a period that women experience physiological changes and eventually role change (Das2013). Therefore, women are prone to seek out information necessary to meet the demand posed during pregnancy. This information is delivered during the antenatal visits. Complications are detected during the antenatal care and professionals deliver this care using the World Health Organization antenatal guidelines. During the visit, there is exchange of information between the nurses/midwives and the pregnant mothers. In Nigeria, healthcare professionals have a legal responsibility to focus on the health and well-being of pregnant women. Accurate and timely information exchange must take place. This information, if well delivered, must help the women's decision-making process regarding the antenatal and postnatal care.

To reduce the maternal mortality, the antenatal care service provider such as nurses and midwives must furnish the pregnant women with evidenced-based information through health education. Through information, knowledge is impacted. Thus, the health knowledge of the pregnant women is improved in the area of engaging in preventive health behavior and improving self-care abilities.

Many authors have identified various other means by which pregnant women obtain information about pregnancy (Das, 2013; Dairo\&Owoyokun, 2010). Sources of information, according to these authors, include healthcare personnel, family members/relatives, friends, and the internet. Lev (2013) reported that in developing countries, pregnant women use their relatives, especially mothers and mothers-in-law, as their source of information. Although using relatives and family as a source of information is good, it also comes with some major disadvantages such as women gleaning and embracing misconceptions about pregnancy from older women. Pregnant women seek information primarily about the pregnancy, postnatal, parenting, breast-feeding, immunization programs, and family planning (Ebijuwa,Ogunmodede\&Oyetola, 2013). Moreover, review of literature 
revealed that doctors, nurses and midwives are primarily consulted during complications (Sharma \& Sharma, 2012). This has contributed to maternal mortality rate.

Information and advice provided to pregnant women ought to enable women to identify pregnancy-related problems when they occur, as well as engaging in preventive health practices that would lead to the safe delivery of their child. However, information exchange is limited because of the workload of nurses and midwives, inadequate access to the internet and other communication sources, and the ability of the women to act on the information. Most research on pregnancy-information needs of pregnant women has been conducted in Western countries. However, little information is available on the information-seeking patterns of pregnant women in Nigeria. In Lagos State, especially in General Hospitals, little is known about the pregnancy-related information needs of pregnant women. This study describes the pregnancy-related information needs of pregnant women, looking specifically at their information-seeking patterns, identifying the barriers to information seeking and how some demographic variables predict their information seeking pattern.

\section{Research Questions}

1. What is the level of pregnancy information needs among the pregnant women attending antenatal clinic of Ikorodu General Hospital, Lagos State?

2. What is the level of information-seeking patterns among the pregnant women attending antenatal clinic of Ikorodu General Hospital, Lagos State?

3. What are the perceived problems inhibiting information-seeking needs of pregnant women in the study area?

4. Would pregnant women demographic variables significantly predict their information-seeking patterns?

\section{Materials and Methods}

This was a descriptive cross-sectional study. Structured questionnaires were administered to collect data from pregnant women attending the antenatal clinic.

\section{Research setting and population}

The study was carried out in a General Hospital in Lagos State which provides antenatal services to pregnant women. The clinic is attended mainly by women in the lower class. The study population consisted of consenting pregnant women, age 18 years and above, attending the antenatal clinic. From the health records, the hospital sees an average of 196 pregnant women 
per week and 640 per month. A sample size of 246 respondents was determined using Yamane Taro formula. The first 246 pregnant women willing to participate in the study were offered the chance. However, only 228 out of the 246 questionnaires were adequately filled and analyzed. Thus, $92.7 \%$ respondent success rate.

\section{Instrument for Data Collection}

A designed questionnaire tagged Pregnancy-Related Information Seeking Pattern Questionnaire (PRISPQ) was used to collect data from the participants. It comprised of five sections: Section A - Demographic Data Inventory; Section B: Sources of Information on Antenatal Care - 13 items; Section C: Information Seeking Needs - 12 items; Section D: Perceived Problems Inhibiting Information Seeking Needs - 10 items; Section E: Information Seeking Types - 10 items. The levels of information-need and information-seeking were categorized as high (35-50), moderate/average (18-34) and Low (1-17). Maximum attainable score was 50. Content and construct validity was ensured whereby 3 academicians reviewed the instrument. Internal consistency of the questionnaire was 0.78 .

\section{Data Collection}

The study was collected between November and December 2015. Before administering the questionnaire to the pregnant women, they were enlightened on the topic, how to respond to the questionnaire, and the importance of the research. Printed questionnaires were handed out to the pregnant women who consented to participate during their antenatal clinic days. Completed questionnaire was received back immediately. Participants were instructed not to put their names on the questionnaire for confidentiality purpose. The study was approved by the Babcock University Health and Research Ethic Committee (BUHREC) and verbal informed consent was obtained from each participants.

\section{Method of Data Analysis}

Data obtained was analysed using SPSS (Statistical Package for Social Sciences) version 21.0. Descriptive statistics (mean, standard deviation, percentage and frequency distribution) were used to describe the data. Regression analysis was used to determine the predictive correlation of the variables. Level of significance was set at $P<0.05$.

\section{Results}

The results for each research questions and hypothesis are presented separately. 
Table 1: Descriptive Presentation of Pregnant Women's Demographic andObstetric Variables $(\mathrm{N}=228)$

\begin{tabular}{|c|c|}
\hline Variables & $\mathrm{n}(\%)$ \\
\hline Age & \\
\hline $18-20$ & $17(7.5 \%)$ \\
\hline $21-25$ & $43(18.9 \%)$ \\
\hline $26-30$ & $63(27.6 \%)$ \\
\hline $31-35$ & $57(25.0 \%)$ \\
\hline $36-40$ & $27(11.8 \%)$ \\
\hline $41-45$ & $13(5.7 \%)$ \\
\hline $46-50$ & $8(3.5 \%)$ \\
\hline Marital Status & \\
\hline Single & $59(25.9 \%)$ \\
\hline Married & $143(57.5 \%)$ \\
\hline Separated & $26(11.4 \%)$ \\
\hline Divorced & Nil \\
\hline Religious & \\
\hline Christianity & $89(39.0 \%)$ \\
\hline Islam & $131(57.5 \%)$ \\
\hline Others & $8(3.5 \%)$ \\
\hline Number of Delivery & \\
\hline None & $51(22.4 \%)$ \\
\hline One & $73(32.0 \%)$ \\
\hline Two & $75(32.9 \%)$ \\
\hline Three \& Above & $29(12.7 \%)$ \\
\hline Gestational Period & \\
\hline First Trimester & $52(22.8 \%)$ \\
\hline Second Trimester & $72(31.6 \%)$ \\
\hline Third Trimester & $104(45.6 \%)$ \\
\hline
\end{tabular}

More than half $(51.8 \%)$ of the women want information on sex in pregnancy at all times. $43.4 \%$ needed information on the use of drugs, while only $31.6 \%$ needed information for birth delivery. Only $43.9 \%$ of the respondents often needed information on preparation for labour and delivery. However, $48.7 \%$ and $46.9 \%$ never needed information on work and alcohol consumption respectively.

Women in this study were likely to seek information on baby's growth and development (74.6\%), childbirth preparation (72.8\%), breastfeeding (70.6\%), labour and delivery (70.2\%) and lifestyle during pregnancy $(69.7 \%)$. Less than half $(44.3 \%)$ of the women were unlikely to seek information on caring for the new born.

More than half $(52.2 \%)$ of the respondents depend on their doctors for information, followed by their mother in law (48.7\%) while the least source of information is books/magazines. 
Table 2: Information on the level of pregnancy information needs and information seeking by the pregnant women

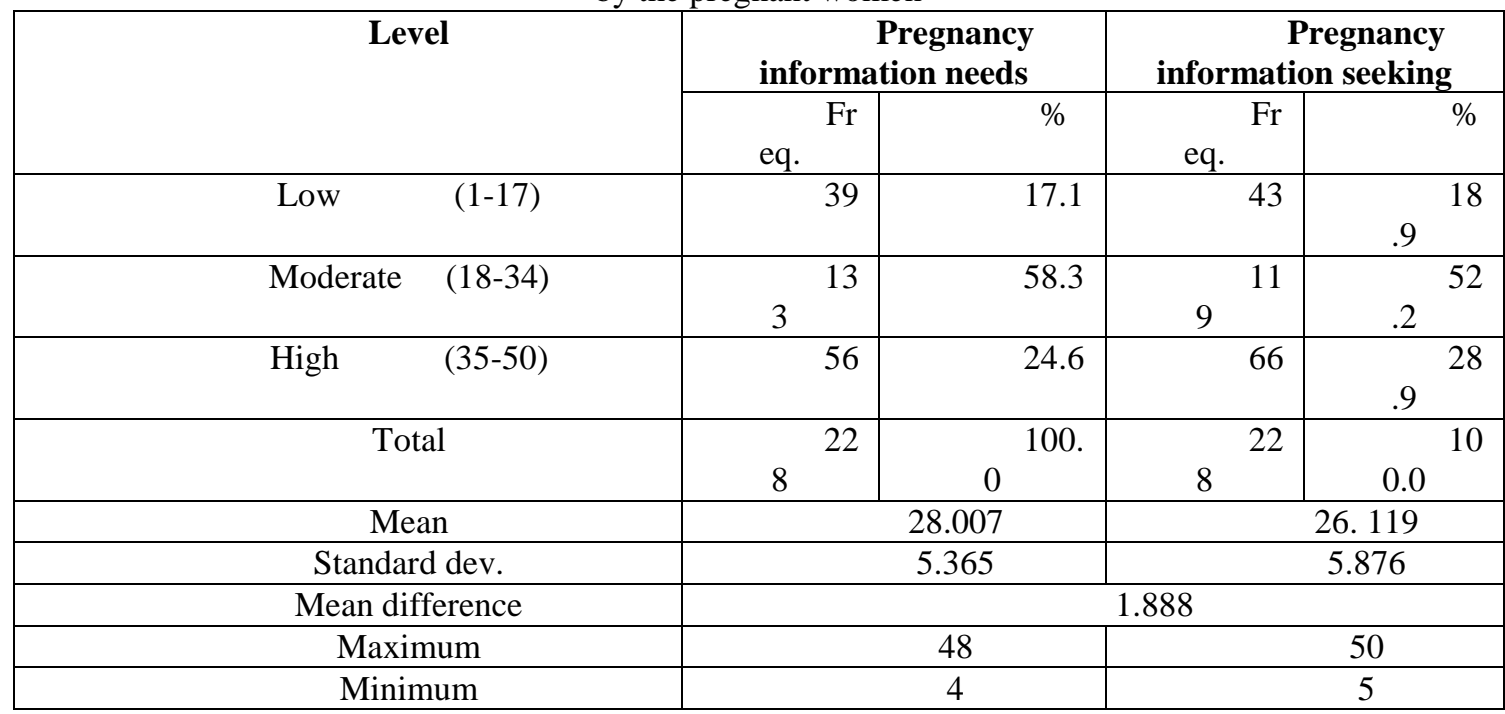

In order to answer research questions 1 and 2 on the levels of information-need and information-seeking, a descriptive analysis was done. Table 2 above, presents the levels of information-need and informationseeking were categorized as high (35-50), moderate/average (18-34) and Low (1-17). It was found out that majority of the pregnant women in the study area had moderate level of pregnancy information needs $(58.3 \%)$ and information-seeking (52.2\%). It could be deduced from this results that the level of pregnancy information-needs among the pregnant women was not significantly different from their information-seeking behavioral patterns (mean difference is 1.888). This might also be as a result of their needs that revolved round women's belief about sexual needs during pregnancy and safe pregnancy delivery.

Table 3: Perceived Problems Inhibiting Information Seeking Needs

\begin{tabular}{|c|c|c|c|}
\hline $\mathrm{N}$ & Perceived Inhibitors & es & $\begin{array}{l}\text { Per } \\
\text { cent }\end{array}$ \\
\hline & No one to discuss my pregnancy with & 01 & $3^{44 .}$ \\
\hline & The health staff attitude is not good & $\begin{array}{ll} & 8 \\
1 & \end{array}$ & $5^{35 .}$ \\
\hline & I feel shy asking information & $\begin{array}{ll}9 \\
1\end{array}$ & 939. \\
\hline & $\begin{array}{l}\text { No need to know more about my pregnancy, } \\
\text { as I already know everything }\end{array}$ & $38^{1}$ & 50. \\
\hline & The healthcare professionals are not friendly & $\begin{array}{ll}7 \\
7\end{array}$ & $8^{33 .}$ \\
\hline & $\begin{array}{l}\text { Lack of discussion focus by health } \\
\text { professional }\end{array}$ & $6^{9}$ & $\begin{array}{ll}42 . \\
1\end{array}$ \\
\hline
\end{tabular}




\begin{tabular}{|c|c|c|cc|}
\hline & $\begin{array}{l}\text { I have to wait a lot to see the doctor or } \\
\text { healthcare professional }\end{array}$ & 47 & \multicolumn{2}{|c|}{64.} \\
\hline Too much information stresses me & \multicolumn{2}{|c|}{6} & \multicolumn{2}{|c|}{29.} \\
\hline & I am scared of asking information & 7 & \multicolumn{2}{|c|}{38.} \\
\hline
\end{tabular}

Waiting for a long hour to see the doctor or healthcare professional $(64.5 \%)$ was a major barrier to information seeking among these women. Over $60 \%$ of the participants were not seeking for pregnancy-related information because of their knowledge level about pregnancy. They claimed that there is no need of knowing anything as they already knew everything. A little less than half (44.3\%) of the women perceived lack of availability of resource persons as preventing them from seeking information about their pregnancy. Lack of proper discussion by health professional is also perceived as a barrier among these women $(42.1 \%)$.

Table 4: Summary of Analysis of variance of the predictive power of age, religion, and marital status on information seeking pattern

\begin{tabular}{|c|c|c|c|c|c|c|c|}
\hline & $\begin{array}{ll}\text { Source of } \\
\text { variation }\end{array}$ & SS & Df & MS & F.cal & F table & Sig. \\
\hline \multirow[t]{4}{*}{ Age } & Between group & 379.194 & 6 & 63.199 & & & 0.01 \\
\hline & Within group & 1386.554 & 221 & 6.274 & $10.073^{*}$ & 3.850 & \\
\hline & Total & 1765.748 & 227 & & & & \\
\hline & \multicolumn{7}{|c|}{$R=.432 ; R^{2}=.187 ;$ Adj. $R^{2}=.183 ; F_{(6,221)}=10.073 ; p<.05$} \\
\hline \multirow[t]{4}{*}{ Religion } & Between group & 240.600 & 3 & 80.200 & & & \\
\hline & Within group & 2086.784 & 224 & 9.316 & $8.609^{*}$ & 3.850 & .000 \\
\hline & Total & & 227 & & & & \\
\hline & \multicolumn{7}{|c|}{$R=.511 ; R^{2}=.261 ;$ Adj. $R^{2}=.247 ; F_{(3,224)}=8.609 ; p<.05$} \\
\hline Marital & Between group & 405.112 & 4 & 101.278 & & & \\
\hline \multirow[t]{3}{*}{ Status } & Within group & 1982.247 & 223 & 8.889 & $11.394 *$ & 3.380 & .013 \\
\hline & Total & & 227 & & & & \\
\hline & \multicolumn{7}{|c|}{$R=.307 ; R^{2}=.094 ;$ Adj. $R^{2}=.088 ; F_{(4,223)}=11.394 ; p<.05$} \\
\hline
\end{tabular}

\section{*Significant at $<0.05$ alpha level}

The hypothesis stating that demographic variables (age, religion, and marital status) of pregnant women will not significantly predict their information seeking pattern was rejected by the outcome of this study. Going 
through the results in Table 3, the calculated value of $\mathrm{F}$ for age, religion and marital status of pregnant women were 10.073, 8.609, and 11.394 respectively, which are greater than the critical value of $\mathrm{F}=3.850,3.850$, and 3.380 respectively. It was observed that age, religion, and marital status accounted for $18.3 \%, 24.7 \%$, and $8.8 \%$ variability of information seeking pattern observed among the pregnant women respectively. This indicates that socio-demographic variables of the pregnant women significantly predicted their information seeking pattern.

Table 5: Beta Coefficients and t Ratio for Relative Contributions of age, religion, and marital status to the prediction of information seeking pattern

\begin{tabular}{ccccccc}
\hline & \multicolumn{2}{c}{$\begin{array}{c}\text { Unstandardized } \\
\text { Coefficients }\end{array}$} & $\begin{array}{c}\text { Standardized } \\
\text { Coefficients }\end{array}$ & t-ratio & Sig. \\
\cline { 2 - 5 } & B & Std. Error & Beta $(\beta)$ & & \\
\hline (Constant) & 33.807 & 7.115 & & $16.444^{*}$ & .000 \\
Age & .201 & .135 & .300 & $6.335^{*}$ & .001 \\
Religion & .298 & .038 & .372 & $8.419^{*}$ & .000 \\
Marital Status & .167 & .047 & .261 & $4.456^{*}$ & .013 \\
\hline
\end{tabular}

*Significant at 0.05 level

a. Dependent Variable: information seeking pattern.

The results in Table 5 revealed the strength of causation of the predictor variable on the criterion variable. The most potent predictor of information seeking pattern among the predictor variables of the study is religion $(\beta=.372 ; \mathrm{t}=8.419 ; \mathrm{p}<.05)$. Age is the next potent factor $(\beta=.300$; $\mathrm{t}=6.335 ; \mathrm{p}<.05)$, and lastly by marital status $(\beta=.261 ; \mathrm{t}=4.456 ; \mathrm{p}<.05)$ in the prediction of information seeking pattern among the pregnant women.

\section{Discussion}

The outcome of the first and the second research questions revealed that majority of the pregnant women in the study area had moderate level of pregnancy information needs (58.3\%) and information-seeking (52.2\%). The women in this study claimed that sex in pregnancy WAs the most pregnancy related information needed all the time. This finding may be attributed to the women's belief about having sexual intercourse during pregnancy. The reduction in frequency of sexual intercourse during pregnancy was credited to changes such as physiological, psychological, and emotional states of the women; thereby leading to reduction in sexual desire (Sharma \& Sharma, 2012; Orji, Ogunlola, \&Fasuuba, 2002,Shojaa, Jouybari, \&Sanogoo, 2009). Sense of decreased attractiveness as well as usual aches and pains of pregnancy, nausea and vomiting may contribute to reduced frequency of sexual intercourse among pregnant women (Shojaa, Jouybari, \&Sanogoo, 
2009). Also, the study of Ijumba et al. (2008) established that managing sex during pregnancy is critical for many spouses especially the women. We may speculate that since sex education is important during pregnancy to this women, nurses and midwives should endeavour to enlighten them on the pros of engaging in this practice. Patient teaching should therefore focus on correcting their misconceptions such as fear of rupturing the membrane and miscarriages that are perceived to occur with sex.

Information-seeking pattern of this women was centred on having safe pregnancy delivery. This was evidenced by the number of women claiming to seek out information on the foetus growth and development. Childbirth delivery, nutrition during pregnancy, and health and wellness. This is in line with the findings of Odujirin (2011) and Saleh et al (2011) who opined thatpregnant women want the best for themselves and their foetuses. This takes into account that every woman is at risk of experiencing sudden and unexpected complications during pregnancy, childbirth and following delivery, however, scientific information through health practitioners can reduce the risk of illness and death (both maternal and infant) considerably.

Participants in this study highly sought for information from medical doctors. The least area of sources for information was from the books and magazines. The reason for this may be that an average African man lacks good reading culture. This supports the assertion of Adenguga, Adenuga and Ayodele (2013) that if you want to hide anything for Nigerians, hide it in a book. Also, the high cost of buying relevant books is also an issue, which may be as a result of poverty levels of some Nigerians.

In this study, the major barriers to information seeking among pregnant women was thewaiting for a long hour to see the doctor or healthcare professional, high confidence in their pregnancy knowledge level, and unavailability of healthcare personnel that could assist with information as the need arises. This result corroborates the previous findings of Nwagwu and Ajama (2011), Shieh, Broome, \& Stump (2010) and Stekelenburg et al (2004) who reported that women had low confidence and trust on the services provided by the healthcare providers as a result of limited time spent with them during their hospital visits.

The pregnant women'sages, religions, and marital status variables predicted their information seeking pattern. This study sharply contradicts the earlier findings of Ebijuwa, Ogunmodede\&Oyetola (2013), and Sharma and Sharma, (2012) who found no significant differences in antenatal care usage between women of different socio-economic variables. On the other hand,the findings of Jody et al (2014)which established that demographic characteristics such as younger age, higher socio-economic status, and being 
married have been shown to positively influence information seeking, lend credence to this study.

\section{Conclusion}

The women in this study reported some pregnancy-related information needs. The pattern at which they seek out information is similar to what is known previously in literature. Poor perception of the quality of care as reported in terms of long waiting time in the hospital and unavailability of healthcare personnel to attend to their information was considered major barriers to information seeking in this study. In addition, certain demographic variable such as age and religion predicted the pregnant women information seeking pattern. The study further revealed that the level of pregnancy information needs among the pregnant women was not significantly different from their information-seeking behaviour. On the basis of this, adequate, timely and professional interventions to promote meeting pregnant women information needs should be developed.

\section{Acknowledgement}

The authors thank the pregnant women for participating in this study and all the nursing staff of the hospital who made the study possible.

\section{References:}

1. Adenguga, R.A., Adenuga, F.T., \&Ayodele, K.O. (2013). Organizational commitment and turnover intention among private universities' employees in Ogun State, Nigeria. Open Journal of Education, 1(2), 31-36.

2. Char, A., Saavala, M., \&Kulmala, T. (2010). Influence of mothers-inlaw on young couples'

3. family planning decisions in rural India. Reproductive health matters, 18(35), 154-162.

4. Dairo, M.D. \&Owoyokun, K.E. (2010).Factors affecting the utilization of antenatal care services in College Of Medicine Ibadan, Nigeria.Benin Journal of Postgraduate Medicine, 12(1): 1-12

5. Das, A. (2013): Information-Seeking among Pregnant Women: A Mixed Method Approach. Electronic Theses, Treatises and Dissertations: $\quad$ Paper $7348 . \quad$ Retrieve from http://diginole.lib.fsu.edu/etd.

6. Demographic Health Services (2015). Demographic and health surveys 2015. Retrieved from

7. http:dhsprogram.com/

8. Ebijuwa, A. S., Ogunmodede, T. A., \&Oyetola, S. O. (2013). Health Information Need and 
9. Information Sources of Pregnant Women in Ogbomosho Metropolis, Oyo State, Nigeria. Library Philosophy and Practice, 0_1.

10. Frawley, J., Adams, J., Broom, A., Steel, A., Gallois, C., \&Sibbritt, D. (2014). Majority of

11. women are influenced by nonprofessional information sources when deciding to consult a complementary and alternative medicine practitioner during pregnancy. The Journal of Alternative and Complementary Medicine, 20(7), 571-577

12. Jody R. L, Chin Hwa Y., Dahlem, J. V., Richard, M. K. \&Adanu, M. B. (2014). Examining

13. antenatalhealth literacy in Ghana. Journal of Nursing Scholarship, 46:6,432-440.

14. Lev, E. (2013): Prenatal googling: online Information Seeking by Israeli women during pregnancy. International Review of Social Science (IRSS), 3(2), 69-87

15. Lucia, D'Ambruoso. (2005).Midwives Attitudes to Women in Labour in Ghana. Accra, Ghana: Mikono Publisher.

16. Nikiéma, B., Beninguisse, G., \& Haggerty, J. L. (2009). Providing information on pregnancy

17. complications during antenatal visits: Unmet educational needs in sub-Saharan Africa. Health Policy and Planning, 24(5), 367-376.

18. Nwagwu, W. E., \&Ajama, M. (2011). Women's health information needs and information

19. sources: a study of a rural oil palm business community in SouthWestern Nigeria.

20. Annals of Library and Information Studies, 58(5), 270-281.

21. Odujinrin, O. (2011). Women's reproductive health and household food securities in Africa: Aten-year review (1986-95) of maternal mortality at the Lagos University Teaching Hospital (L.U.T.H.).Annals of Internal Medicine, 35(12), 67-74.

22. Orji, E. O., Ogunlola I. O., \&Fasuuba O. B. (2002). Sexuality among pregnant women in

23. South-west Nigeria. Journal of Obstetrics and Gynecology, 22; 166168.

24. Saleh, A.G. \&Lasisi, F.I. (2011). Information needs and information seeking behavior of rural women in Borno State, Nigeria. Library Philosophy and Practice. World Libraries, 18, 2.

25. Sharma, M., \& Sharma, S. (2012).Knowledge, attitude and beliefs of pregnant women towards safe motherhood in a rural Indian setting.Social Sciences Directory, 1(1). 
26. Shieh,C.S.,Broome,M.E., \& Stump, T.E. (2010). Factors associated with health information-seeking in low-income pregnant women. Women \& Health. 50 (5), 426-442.

27. Shieh, C.S., McDaniel, A. \&Ke, I. (2009). Information-seeking and its predictors in low income pregnant women. Journal of Midwifery \&Women's Health 54,364-72.

28. Shojaa M, Jouybari L, \&Sanogoo A. (2009).The sexual activity during pregnancy among a group of Iranian women. Archives of Gynaecologyand Obstetrics, 279: 353

29. Song, H., Cramer, E. M., McRoy, S., \& May, A. (2013). Information needs, seeking

30. behaviours, and support among low-income expectant women. Women \&Health, 53(8), 824-842.

31. Stekelenburg, J., Kyanamina, S., Mukelabai, M., Wolffers, I., \&Roosmalen, J. (2004).

32. Waiting too long: Low use of maternal health services in Kalabo, Zambia. Tropical Medicine \& International Health, 9(3), 390-398.

33. Taylor, K. (2008) The need for antenatal education that gives women what they want. ThePractising Midwife 11, 4-5.

34. World Health Organization. (2015). Trends in maternal mortality:1990 to 2015. Geneva: Author. 